\title{
Viaje al paraíso perdido: metamorfosis del viaje a Damasco (I)
}

\author{
Ángel Clemente Escobar \\ Universidad Complutense de Madrid \\ angclemen@gmail.com
}

Recibido: 30 de abril de 2011

Aceptado: 13 de mayo de 2011

\section{Resumen}

El presente trabajo recupera las transformaciones más relevantes que ha sufrido el imaginario de la ciudad de Damasco en los libros de viaje, con especial atención a los viajeros modernos. Esta imagen, que dependerá de las tradiciones literarias de los sujetos, pero también de las transformaciones históricas y materiales de la ciudad, presenta en principio un modelo de ciudad exótico-oriental, el cual será frecuentemente transgredido a partir de la segunda mitad del siglo XIX. Para completar esta panorámica, en la segunda entrega recurriremos al comparatismo para identificar los cambios que se producen en la visión que brindan los textos de algunos de los elementos urbanos más significativos de la ciudad.

Palabras clave: Literatura de viajes, viajeros, imaginario, Damasco.

Title: Travel to the lost paradise: metamorphosis of travel to Damascus (I)

Abstract

This paper brings the most significant transformations undergone by the imagery of the city of Damascus in travel books, paying a special attention to the modern traveller. This image, which relies on the literary traditions of the subjects, but also on the historical and material changes suffered by the city, suggests initially an exotic-oriental city model, which is often transgressed since the second half of the nineteenth century. To complete this picture, in the second part we will resort to comparatism in order to identify the changes produced in some of Damascus' most significant urban elements according to the texts.

Keywords: Travel literature, traveller, imagery, Damascus.

\section{Índice}

1. Introducción

2. Metamorfosis del viaje a Damasco durante los siglos XVIII, XIX y XX

\section{Introducción}

Hablar sobre Damasco es remontarse a los orígenes de la Historia. Más aún, culturalmente la ciudad está relacionada con la genealogía de la especie. La mitología nos cuenta que Dios hizo a Adán con barro del río Barada, además de ser considerada durante siglos el Jardín del Edén, el paraíso bíblico de donde fueron expulsados nuestros primigenios ancestros, o el lugar donde Caín hizo derramar "la sangre 
del justo", antes de construir Enoc, la primera ciudad de la historia. En sus alrededores se encuentran restos de época calcolítica, hacia el 4000 a. de c., ha pertenecido a imperios como el antiguo Egipto, Roma, Bizancio, Macedonia, a los amorreos, los arameos, los asirios, al Imperio Otomano, a otras ciudades de las que hoy sólo podemos recorrer sus vestigios, como Babilonia, antes de ser en época contemporánea capital del estado sirio. Ha sido conquistada por Alejando Magno, por los persas, los fatimíes, los turcos, los mongoles; ha sido capital de imperios como el selyúcida o el árabe de los Omeya; ha sido saqueada, devastada y quemada en incontables ocasiones. Recorrer su historia es recorrer la Historia: para el viajero occidental el viaje a Damasco es percibido en primer lugar como un viaje a los orígenes.

Ese era el motivo de los primeros viajeros europeos a la ciudad, peregrinos del primer Medievo que se dirigían a Oriente con el objetivo de visitar Tierra Santa, en busca de un origen religioso. En La Biblia, la ciudad aparece como un principado arameo desde los tiempos del rey David (1R 11: 24), además de ser un topónimo frecuente en el Antiguo Testamento; pero se convertirá en un enclave de culto para el cristianismo por ser el lugar de la conversión de San Pablo según el Nuevo Testamento (Hch 9) en el primer siglo de nuestra era. Esa motivación religiosa era la del obispo galo Arculfo, que la visitó aproximadamente en el año 670, es decir en los primeros años del califato Omeya, el cual es citado por Colin Thubron en su semblanza sobre la ciudad (Thubron 2002: 200). En los siglos posteriores Damasco será también, y principalmente, tierra sagrada para una religión islámica en expansión; lugar donde quedaría simbolizado gran parte del legado del profeta Mahoma a partir de su capitalidad del imperio árabe, apenas 40 años después de la Hégira, además de ser el punto de inicio de la peregrinación a la Meca, con la caravana que lleva su nombre.

Hay que tener en cuenta, para apreciar el valor de estos primeros viajes desde el occidente medieval, que Oriente era percibido como algo remoto, una confusa realidad geográfica y política, desconocida para la gran mayoría de los occidentales, en la que se encontraba Bizancio, pero que se limitaba al mediterráneo y sus entornos, y habrá que esperar a los viajes de Marco Polo para que estos límites se extiendan por toda Asia. Este primer imaginario oriental, damasceno concretamente, se nutrirá de una tradición erudita, basada en La Biblia y en las fuentes clásicas antiguas, y de otra de carácter más popular sustentada en leyendas o en los relatos deformados de los peregrinos, viajeros y mercaderes (Balard 1988: 17).

En el 1173, un año antes de la conquista de Saladino, será visitada por el rabino navarro Benjamín de Tudela, en un momento en el que su valor simbólico para ambas religiones, la cristiana y la 
musulmana, se encuentra en alza. Su descripción de la ciudad es una de las más importantes de todo el medievo:

Es una ciudad hermosa, grande y circundada de una muralla; tierra de huertas y vergeles en un trayecto de quince millas a la redonda; no se ve una ciudad tan fructífera como ella en todo el país. Hacia ella descienden, desde el monte Hermón, los ríos Amana y Parpar, pues se asienta bajo el monte Hermón. El Amana desciende por medio de la ciudad y las aguas son conducidas por medio de acueductos a todas las casas de los notables, a las calles y a los zocos [...], En el palacio hay casas construidas en oro y cristal, y cuando la gente va rodeada el muro, se ven los unos a los otros. Hay columnas recubiertas de oro y plata, y asimismo hay columnas de mármol polícromo. (Tudela 1982: 84)

En este fragmento se encuentran ya algunos de los ingredientes que aparecerán continuamente en las descripciones de la ciudad, los cuales irán creando un universo material y simbólico en torno a ella. En primer lugar tenemos la muralla, la cual fue construida en el siglo IX a. de c. (Martín Asuero 2004: 17), destruida y reconstruida en varias ocasiones, pero que conforma junto a la vegetación, los huertos y el vergel, y los ríos Amana (Barada) y Parpar $^{1}$, la imagen con la que emprenderán su viaje los viajeros posteriores: el Gutha, el oasis amurallado. Vemos otro ejemplo, ya en tiempos de Saladino, en el viajero y literato andalusí Ibn Yubair (1145-1217), quien en su visita a la ciudad escribió: "Es el Paraíso de Oriente, la cuna de su gentil y radiante belleza [...]. La adornan las flores de hierbas de dulce aroma y la engalanan las vestiduras de brocado de sus jardines" (Thubron 2002: 201). Desde este momento y hasta los textos contemporáneos será frecuente para los viajeros, en virtud de esa imagen, la asimilación de Damasco con el Paraíso Terrenal.

Todavía en el siglo XIV, antes de la devastación, destaca la figura de Jehan de Mandeville (?-1372) natural de Lieja, quien escribió The voyage of Sir John Mandevile, el cual, redactado alrededor de 1356 se convirtió en el libro más popular en los dos siglos posteriores. Según nos cuenta emprendió su viaje el día de San Miguel de 1322, con la intención de, en calidad de peregrino, visitar Jerusalén. Resultado de ese viaje sería este libro lleno de excentricidades y fantasiosas invenciones en el que algunos de sus capítulos tienen como objeto Damasco. En el siglo XIX la crítica se dio cuenta de que el libro había sido escrito enteramente sin salir de casa, y compuesto con la ayuda de una nutrida biblioteca (Morales

\footnotetext{
1 Tudela recoge los nombres de la Biblia: "¿Acaso el Abaná y el Farfar, ríos de Damasco, no son mejores que todas las aguas de Israel?" (2R 5: 12). En realidad el Parpar, o Farfar, es una de las extensiones del Barada, conocido actualmente como Nahr el-Awaj.
} 
Osorio y Fernández Hoyos 2006: 337). No serán pocos los fantasiosos ejemplos de este tipo a lo largo de toda la Edad Media e incluso después.

Los últimos testimonios reales de la ciudad antes de la devastación son los de tres peregrinos de la Toscana (Thubron 2002: 203): un noble florentino llamado Frescobaldi; Simone Sigoli, miembro de una importante familia de mercaderes florentina, y un tercero Ilamado Giorgio Gucci. En estos viajeros los conocimientos acerca de la ciudad y su cultura son bastante toscos, están interesados principalmente en los lugares santos y no aparecen topónimos locales u otros conocimientos sobre la zona. El primero de ellos la describe de la siguiente manera:

La città di Damasco è tuta murata, ma non ha fossi se non in alcuno luogo, ed è antica e grossa città, e ha grandissimi borghi che fanno più gente che'l corpo della città; e in molte luogora le case de' borghi sono appiccate alle mura della città, e'borghi non hanno nè mura, nè fossi, nè steccati. (Frescobaldi 1818: 171)

Estas oleadas de peregrinos, de mentalidad y cultura indudablemente medieval, se completaron desde el siglo XIII con la visión de los primeros mercaderes venecianos y genoveses, los cuales dejaban testimonio de una visión más moderna y empírica.

De la devastación y el saqueo de la ciudad tiene constancia Europa gracias a un testigo, Johann Schiltberger (1380-1440), mercenario bávaro perteneciente al ejército húngaro que cayó prisionero de los turcos en la batalla de Nicópolis en 1396. Posteriormente, caerá en manos de los mongoles, quienes lo obligarán a unirse a sus tropas. Será así como dé cuenta en su libro de viajes -cuya primera edición data aproximadamente del año 1460-, de vuelta a tierras germanas, del saqueo de la ciudad $y$, entre otros, del gran incendio de la mezquita. En todo caso, algunos problemas con las fechas hacen sospechar que el testimonio pueda ser falso. Tras la devastación, los mamelucos lograron devolverle parte de la vida que Tamerlán le quitó, hubo un importante repunte del comercio, que en todo caso no volvió a ser el mismo desde la expansión del comercio veneciano y la apertura de la ruta de las indias.

Ya en pleno siglo XVI aparece la figura de Ludovico di Varthema, noble boloñés, quien llegó a la ciudad para aprender el árabe (Varthema 2004: 42), antes de convertirse al islamismo y unirse a una caravana de peregrinos hacia la Meca en 1503. Su carácter renacentista y su educación, sin embargo, no le impedirán 
afirmar que hay unicornios en la $K a a b a^{2}$ de la mezquita de esta ciudad $^{3}$. De Damasco, en la línea de lo que venimos viendo desde arriba, destaca sus abundantes y excelentes frutos y su abastecimiento de agua, alusiones recurrentes a la hora de describir el vergel. Es uno de los últimos testimonios que encontramos del período mameluco, antes de que Salim I la tomase en 1516 para los otomanos, imperio al que pertenecerá, no sin algunas interrupciones, hasta la I Guerra Mundial.

En este momento, a pesar de ser sólo una capital provincial, Damasco seguirá conservando su rol comercial y artesanal, además de continuar siendo el punto de partida de la caravana anual a La Meca. La actividad burocrática del Imperio Otomano y sus crecientes relaciones con las cortes europeas dan a conocer la ciudad a los occidentales, además del también creciente número de testimonios de peregrinos que les llegan. No obstante nos parece adecuado pensar, a pesar de todas estas manifestaciones, que la adopción del antropocentrismo renacentista, lo cual es lo mismo que decir el eurocentrismo, que se ve reforzado con el descubrimiento del continente americano, será un punto determinante para la generalización de una estética de lo exótico, que debe partir necesariamente de unas diferencias culturales y políticas reconocidas con respecto a la norma (González Alcantud 1988: s/p). El gusto por lo oriental prolifera en toda Europa, aparecen los primeros embajadores de las cortes europeas en el Imperio Otomano durante el siglo XVI, los pintores occidentales comienzan a hacer los primeros retratos de sus habitantes y se inicia también el estudio de las lenguas y literaturas orientales en el XVII (Soriano Nieto 2009: 79).

Durante los siglos XVI y XVII proliferan extensamente estos viajeros, entre los que destacan el músico español Francisco Guerrero (1528-1599), que realizó el viaje en 1589 junto a otros peregrinos con la intención de visitar Tierra Santa, del cual dejó constancia en su Viaje de Heirvsalem (Guerrero 1593); Antonio Tereiro que lo hace en su Itinerario de Antonio Tenreyro de 1560 (Martín Asuero 2004: 19); los también portugueses padre Sebastiao Manrique (1590-1669), que

\footnotetext{
${ }^{2}$ La Kaaba es una gran construcción en forma de cubo, en la masjid al-Haram, la Mezquita sagrada de la Meca. El significado de la Kaaba, un cubo vacío, está relacionado con la prohibición de la adoración de figuras u objetos en el islam. Simboliza la unidad de los musulmanes que adoran un Dios único, y representa el lugar al cual han de dirigirse los rezos. Su fundación es atribuida a Abraham.

3 "D'un autre côté de ce temple es un enclos où se trouvent deux licornes vivantes : on les montre comme quelque chose d'extraordinaire, et ce l'est effectivement. Je vais vous dire comment elles sont faites. La plus grande est faite comme un poulain de trente mois et a une corne sur le front, et cette corne a environ trois brasses de longueur. L'autre licorne est faite comme un poulain d'un an et a une corne longue d'environ quatre empans. La couleur de cet animal est comme celle d'un cheval rouan foncé. [...] Ces deux bêtes ont été offertes au sultan de La Mecque comme la plus belle chose qu'on puisse trouver aujourd'hui ou monde" (Varthema 2004: 72-73).
} 
llega a la ciudad en 1630, Pantaleao d'Aveiro y Alvaro da Costa (Graça 1983); o William Lithgow, según Thubron (2002: 206-207) el primer viajero escocés en visitarla, quien terminó siendo juzgado por la inquisición española, entre otras cosas por afirmar que los turcos tenían vallado un jardín en la ciudad donde guardaban el manzano prohibido del edén.

En este siglo XVII destaca igualmente la figura de Monsieur de Thévenot (1633-1667). Este viajero francés describe de forma extensa las puertas y murallas de la ciudad, además de los tradicionales enclaves emblemáticos para el cristianismo, pero además da cuenta de otros elementos que van cobrando importancia conforme entramos en la modernidad, como lo son los bazares (Thévenot 1674: 28-29). También se siente atraído por la Gran Mezquita, la cual, por tener prohibida la entrada a los kuffâr o infieles, describe desde otra más pequeña, esto a pesar de, según su relato, ser invitado a visitarla vestido de turbante, a lo cual se opone para no renegar de su fe ${ }^{4}$. Nos lo cuenta de la siguiente manera:

Du côté du couchant l'on entre dans cette Moofquée, par deux grandes portes de bronze, hautes de prés de quatre toifes, qui font fort bien traaillées, \& pleines de figures bizarres; I'on voit au milieu de chacune vn calice bien gravé. Je vis par ces portes la largeur de la Mofquée, qui peur eftre environ de dix huites toifes; elle a deux rangs de groffes \& grandes colomnes de marbre gris, à la Corinthienne, qui la feparent en trois nefs ; \& toutes ces colomnes foûtiennent à deux vne arcare ; \& au deffus de chaque arcade, il y a deux autres petites arcades, divifées par de petites colomnes ; ce qui reffemble affez à des fenêtres: Le pavé eft tout de belles pierres luifantes comme des miroirs. (Thévenot 1674: 31-32)

Mucho más meticuloso y observador que los anteriores, destaca por sus descripciones arquitectónicas, muy del gusto del barroco, pero también de las relaciones sociales o de los usos y costumbres culinarias de sus habitantes. Su relato es ya un antecedente de las representaciones modernas de la ciudad.

Aún así el viaje a oriente no estaba generalizado ni siquiera en el siglo XVII y habrá que esperar a las primeras décadas del siglo XVIII, con la traducción al francés de Las mil y una noches, cuando la fascinación por el mundo oriental comience su época de apogeo. Es el ejemplo perfecto de que los esfuerzos a la hora de adquirir

\footnotetext{
4 "Ayant autant que nous pûmes confideré cette mofquée, nous vînmes à vne autre qu'on apelle la grande Mofquée. Je tournay autour pour la voir, a plufieurs fois, par les portes qui eftoient ouvertes, car vn Chrêtien n'oferoit y mettre le pied, n'y mefme s'arréter devant la porte. Quelques Turcs m'offrirent bien de m'y faire entrer avec vn tulban de Turc, mais je ne voulus point accepter cette offre, car eftant reconnu il auroit falu mourir, ne voulant pas (avec la grace de Dieu) renier ma foy" (Thévenot 1674: 31).
} 
conocimientos de las otras culturas no sólo influyen sino que posibilitan la formación de un discurso posterior donde tenga cabida la subjetividad. Es también el siglo de las luces, la razón, el momento donde surgen conceptos como "el buen salvaje" roussoniano, el "contrato social", pero también los primeros frutos del desengaño de la "bondad natural" y el despegue de un individualismo que presidirá a finales de siglo e inicios del siglo posterior el discurso romántico.

\section{Metamorfosis del viaje a Damasco durante los siglos XVIII, XIX y XX}

Estas ideas producen una nueva transformación en el relato y la descripción de la ciudad, y los principios estetizantes del barroco o la mirada mágica de la Edad Media darán paso a una visión mucho más documentalista y de intención didáctica e informativa, que es la que presidirá el relato de viajes en el siglo de las luces, el cual aportará una valiosísimo legado objetivo que posibilitará el desarrollo de una mirada subjetiva posterior. Los juicios empíricos que dependen por tanto de la experiencia se conjugan con la razón kantiana, la cual en tanto que "universal" va a influir en la forma de pensar la alteridad, en un mundo en el que el colonialismo es ya una realidad. En este siglo lo exótico es percibido principalmente en clave de pasado. El buen salvaje es la consecuencia de un primitivismo que tiene como sujeto una civilización que se considera más evolucionada que las demás, y ve en los otros pueblos estadios de la evolución por los que ella ya ha pasado. El viaje a Polinesia, recientemente descubierta para los europeos, es un viaje a épocas prehistóricas, pero el viaje a Oriente se asume más como un viaje a los orígenes de la historia, y se piensa en ciudades como Damasco como un lugar que ha permanecido inalterable desde la época de Jesucristo durante este período.

Entre los que visitaron Damasco se cuenta Richard Pococke (1704-1765), quien comienza su capítulo dedicado a la ciudad con una introducción etimológica e histórica, algo que en mayor medida no estaba presente en los libros de viajes anteriores, o, al menos, no tan desarrollado como en este caso. Además describe los espacios de la urbe más allá de aquellos elementos mítico-religiosos, los espacios bíblicos que en la Edad Media configuraban el itinerario de los peregrinos. Él se refiere además a las casas, las calles, los jardines, hospitales, los cafés, etc., siempre con un afán, no siempre exitoso, de intentar razonar lo que ve bajo una lógica cartesiana. Alude a las costumbres de sus habitantes, a los diferentes grupos sociales, el comercio, los productos, el carácter de sus gente, etc. No en vano, Pockocke, antes que viajero es un estudioso ilustrado, considerado precursor de la egiptología y la antropología por emplear en sus viajes y descripciones un punto de vista que podemos calificar de 
científico. Otro ejemplo paradigmático de este tipo de viajero lo encontramos en el conde de Volney (1757-1820), quien, como nos dice Thubron (2002: 210), pasó 8 meses aprendiendo árabe en un convento en territorio druso. En ambos casos la narración, las peripecias del viajero, reales o no, pierden bastante importancia, por lo que a diferencia de los viajes anteriores lo exótico no es tanto una herramienta para fascinar al lector, sino un objeto que genera curiosidad y demanda conocimiento. Volney se detiene, por ejemplo en dar datos precisos en todo lo referente al número de hombres y caballos de los ejércitos del sultán, u otros muchos datos de carácter cuantitativo.

El imaginario de ciudades como Damasco se ve transformado radicalmente durante este periodo por varios motivos. En primer lugar deja de ser un espacio desconocido para occidente, y ese conocimiento influye en la imagen europea de la ciudad oriental, la cual se ve enriquecida. En segundo lugar se descubre el imaginario que los orientales tienen de sí mismos, y los cuadros de la ciudad y de sus palacios en Las mil y una noches aportan nuevas imágenes a esa construcción mítica damascena.

A pesar de todo este aprendizaje, oriente mantiene las distancias con el viajero occidental; entre otras cosas, además de por ser extranjero, por ser kafir, infiel, y no abrazar la religión del profeta Mahoma. El infiel no puede entrar en la ciudad a caballo, vestir colores sagrados $y$, por supuesto, tiene absolutamente vedado el acceso a la mezquita. Estos motivos son los que llevaron al primero de nuestros viajeros en el siglo XIX, Domingo Badía y Leblcih, a convertirse en Ali Bey el abbassí, y bajo ropas orientales recorrer Arabia, Palestina, Siria y Turquía. Su caso es uno de los más increíbles, paradigmático entre aquéllos que marcaron a fuego el relato de viajes romántico. En realidad se trataba de un espía de Godoy, encargado de tantear una posible expansión de las rutas comerciales españolas. Su obra, escrita originalmente en francés bajo el título Voyages d'Ali Bey en Afrique et en Asie pendant les années 1803, 1804, 1805 et 1807 fue publicada en París en 1816, pero en España era considerado un afrancesado, lo que postergó la aparición de su obra en este país (Martín Asuero 2004: 36). Badía tenía una formación ilustrada, hecho que se ve reflejado en el carácter de su obra, donde predomina una intención informativa, o como nos dice su exégeta: "La disposición del discurso se caracterizó por la búsqueda de un lenguaje económico y transparente, vertido en la forma de una estética empírica, fruto de la observación directa y característica de los viajeros del siglo XVIII" (Almarcegui 2007: 205). Sin embargo se le considera uno de los primeros viajeros románticos, a pesar de que su escritura no lo sea.

Pocos años después, en 1812, llegó a Damasco Johann Ludwig Burkhardt, explorador suizo, aventurero y erudito, que estudió árabe 
en Inglaterra antes de embarcarse. También disfrazado de árabe, se hizo llamar Sheik Ibrahim Abdallah, un mercader. Vivió siendo un pobre, hasta que consiguió dominar el árabe y pudo conocer el Corán y la ley islámica. Sus obras, Travels in Sirya and the Holy Land (1819), donde se refiere a Damasco, junto con Travels in Nubia (1822) y Travels in Arabia (1829), pasaron a formar parte del corpus indispensable de lecturas de los viajeros posteriores antes de emprender su propia aventura, y será citado por Lamartine, Bost y, sobre todo Burton, entre los que visitan la ciudad.

La categoría de lo exótico alcanza su mayor grado de exaltación en el Romanticismo, movimiento en el que la subjetividad y la ideología del individuo marcan las pautas estéticas. El viaje a oriente es un ejemplo de la interiorización del paisaje exótico por parte de los autores, al mismo tiempo que se vislumbra como intento de huida de una razón que no deja de producir sombras y rebeldía frente a la mediocridad que preconizaba la sociedad burguesa. Es la ensoñación de un mundo idealizado que responde a las expectativas de los más altos valores y virtudes de los autores, donde toman forma sus ansias de otredad: el lugar donde la poesía, el misticismo -mediante la idealización de la religión islámica- o el erotismo se encontraban todos a la vez y de manera más rotunda. En este contexto se producen los viajes a oriente de Chateaubriand y Lamartine o Nerval, los cuales marcarán tendencia, además de la pintura orientalista de autores como David, Delacroix, o la música de Saint-Saëns.

El mismo año que Burkhardt, llegó a la ciudad la primera de sus viajeras occidentales, la cual creará toda una leyenda a su alrededor. Se trata de Lady Hester (1776-1839), nada menos que una aristócrata inglesa de tez clara, que entró por la puerta con la cara descubierta, a lomos de un purasangre negro y vestida de hombre (Morató 2006: 96). Se instaló con su séquito en una casa del barrio cristiano, pero posteriormente le pidió al pachá que le buscase otra en la zona más noble de la ciudad, cosa que éste le concedió. Tuvo correspondencia con Ali-Bey. Entre la población fue considerada una reina, y le lanzaban granos de café a su paso mientras que la vitoreaban. Los más poderosos de la ciudad la recibían como invitada -lo hizo hasta el propio pachá (Morató 2006: 99)- y su popularidad se convirtió en leyenda con el viaje que realizó en caballo a Palmyra, junto a su amante inglés, y con su retiro en Djoun (Siria), donde permaneció hasta su muerte.

El viajero inglés George Robinson, que visitó la ciudad en 1830, llegó a caballo, y desde lo alto, con el barrio de Salihiye a sus pies, disfrutó junto a sus acompañantes de una vista que en un primer momento les fascinó: "Burst suddenly upon our delighted fancy" (Robinson 1837: 133), pero una vez a ras de suelo las primeras sensaciones que le produjo la ciudad no fueron de su agrado: 
On a nearer inspection, Damascus does not altogether answer to the expectations held out by its exterior appearance. The ideas of splendor and magnificence promised from afar subside soon after entering the gates; for. Though the one and the other may exist in the palaces of the great, and the private dwellings of the rich, they are not to be met beyond their precincts. (Robinson 1837: 253)

Su obra, Travels in Palestine and Syria, fue publicada en Londres en 1837 y un año después aparece en París la traducción al francés revisada y anotada por el propio autor. Como Lady Hester, quiso entrar montado a caballo, aún a sabiendas de que estaba prohibido, y a los pocos metros de haberse adentrado en la ciudad sus compañeros, un traductor y un ayudante, habían echado el pie a tierra- fue interceptado violentamente, como nos cuenta él mismo:

Whilst riding carelessly along, some hundred yards a-head of them, absorbed in my reflections, two or three ruffian-looking Turks ran suddenly up to me, and seizing hold of the bridle of my horse, asked me in an impetuous tone, if I were not a Djaour or "Infidel." [...] I was torn violently from my horse, and loaded with a volley of imprecations. In a few minutes some hundreds of the inhabitants had collected round me, and I was apprehensive of becoming the victim of a popular tumult [...] some spots of green, the privileged colour, were discovered in my flowered turban, and it was instantly torn off my head. (Robinson 1837: 135-137)

El conocimiento que de la cultura oriental tiene la occidental hace que se acreciente el interés por espacios religiosos, no ya solamente cristianos, que en gran medida continuarán siendo referidos, aunque con una óptica que -como veremos- será cambiante; también se incorporan aquéllos de la religión musulmana, incluso en algunos casos con mayor importancia para estos últimos. Esto será así hasta tal punto que el islam será sublimado por muchos viajeros, como vemos en el caso de Adolfo Mentaberry (Martín Asuero 2004: 80). Pero a pesar de ese conocimiento, para los autores se hace necesaria una simplificación, que en este caso será lo oriental como adjetivo que aglutina todas las características que el lector conoce como tal, por lo que ante todo es una construcción imaginaria. Para Robinson la ciudad sería precisamente el paradigma de ese orientalismo: "But the chief charm of Damascus, that which captivates the European traveler on his arrival, and follows him in souvenir, long after he has quitted it, is its peculiar oriental character". Pero como sabemos lo exótico solo es dable en tanto que se opone a lo local y conocido: "In his wanderings though the city and its environs, he meets with nothing to remind him of home, unless it be suggested by the great contrast of all he sees, as compared with what he has ever seen before", continua Robinson (1837: 254). 
Algo que resaltarán con frecuencia los viajeros modernos será el fanatismo religioso que se vive especialmente en Damasco, en comparación con otras ciudades del Imperio, y a ello se refiere el propio Robinson:

I was well aware that Damascus was one of the few places remaining in the Turkish dominions, where religious fanaticism drew a strong line of distinction between its Mussulman and Christian population. Many are the humiliations to which the latter are exposed. (Robinson 1837: 135)

Ello también había sido resaltado por Badía, justificando con ello la adopción del disfraz:

Cuéntanse ocho sinagogas de judíos, y me aseguraron que entonces los trataban bien. Sin embargo creí notar que el fanatismo del pueblo de Damasco excede al de los de Egipto; pues un europeo no puede sin riesgo presentarse vestido con el traje de su país, y se ve precisado a adoptar el de levante. Un cristiano o judío no puede ir a caballo por la ciudad; ni aun se les permite cabalgar en un asno. (AliBey 1982: 440)

El tema de los viajeros que entran a la ciudad disfrazados será casi un tópico a lo largo del siglo XIX. También lo hizo casi veinte años después Lamartine, y posteriormente Flaubert, Richard Burton, Pierre Loti. Para los ilustrados como Badía el disfraz tenía una función pragmática, les ayudaba a pasar desapercibidos y a integrarse mejor, evitar peligros, etc. Pero, como dice P. Almarcegui, con el viajero romántico (la autora considera a Badía un ilustrado) "esa alteración exterior supuso la necesidad de crear una nueva identidad al margen de los valores culturales habituales. Esto significó una transgresión simbólica con la que se renunciaba a uno mismo para hacerse otro" (Almarcegui 2004: 110).

El caso de Alphonse de Lamartine quien, disfrazado con ropas turcas, llegó a la ciudad con un imponente séquito, ya no podría igualar a Ali Bey o la propia Hester. Sin embargo, la escritura que surgirá del viaje va a ejercer una grandísima influencia, con un estilo exuberante en el que la ciudad alcanza su mayor grado de subjetividad, de tal manera que los elementos urbanos y paisajísticos nos hablan del interior del poeta en clave metonímica. La exaltación del yo romántico es el detonante para que, en un entorno atrayente y lleno de exotismo, se pueda desarrollar esta estética. Su obra, Voyage en Orient: 1832-1833, es también un testimonio de la conquista de Damasco por parte de Ibrahim, bajá de Egipto, a los otomanos.

El viajero del siglo XIX, del cual Lamartine es un buen prototipo, ya no es ni peregrino ni espía, sino que viaja por una 
búsqueda personal. Las experiencias viajeras ya no están reservadas a burócratas o militares o peregrinos, y los autores comienzan a deberse a sus lectores, los cuales pertenecían a una burguesía cuya única forma de viajar era a través de los libros. Su obra aporta los últimos fragmentos a la consolidación de la imagen del viajero romántico como héroe, que en el caso del poeta francés está además presidida por la tragedia: la muerte de su hija cuando el viaje apenas había comenzado.

Con las descripciones románticas como las de Lamartine el misterio y la belleza de Damasco alcanzan las cotas más altas, no porque la ciudad fuese más espectacular en otro tiempo, sino más bien porque la mirada que estos escritores tienen sobre la alteridad se basa más que ninguna otra en el deseo, de tal forma que proyectan sobre la ciudad todo aquello que no poseen en sus vidas occidentales. En palabras de Almarcegui:

El viajero elaboró sus ansiedades en una geografía que acogía la construcción de su mirada, de todo lo que no encontraba en su contexto habitual y que pertenecía al terreno de sus deseos. Como página en blanco ese destino representó una ausencia desde la cual crearse e imaginarse. Poco a poco el viajero, que en el siglo anterior había interpretado Oriente a partir de sus referentes, es decir, de lo que ya poseía, los proyectó mostrando lo que desearía poseer. Oriente fue deseado $y$, por ello, se constituyó como incompleto e irrealizable, pues remitía a una alteridad. De esta manera, por una extraña paradoja, cuanto más se intentó dar forma a este deseo, más se alejaron las representaciones del Oriente real. (Almarcegui 2004: 109)

En este entorno francófono, a raíz de los textos mencionados, que crearán una tendencia literaria, a mediados del siglo XIX se producirá lo que denominamos una explosión orientalista, sobre todo por la proliferación de los Viajes a Oriente -en los cuales, como sabemos, Damasco será un topónimo más que recurrente-, además de la consolidación de una estética exótica orientalizante en la literatura, la música y las artes plásticas.

Los años de gobierno Egipcio de la ciudad, entre 1832 y 1840 , supondrán una época de modernización de la industria y la agricultura, mejoras en la seguridad de las rutas comerciales, todo bajo un gobierno de corte ilustrado e influido por Francia. Sin embargo los cambios producidos chocaron con el talante conservador de los habitantes de Damasco, y las numerosas revueltas unidas al apoyo de las potencias occidentales al Sultán terminaron con el gobierno de Ibrahim.

Damasco había vuelto a manos turcas en 1840. La alianza entre Estambul y las potencias europeas en Crimea frente a Rusia provoca una época de cambio en el Imperio conocida como Tanzimat, de la que deriva una estabilidad a todos los niveles durante la segunda 
mitad del siglo XX; será así como, con la creciente presencia inglesa y francesa en la zona, comiencen a entrar los primeros capitales europeos.

Llegados a estas alturas de siglo volvemos a encontrarnos en un periodo en el que el agotamiento de un modelo literario que está produciendo sus últimas obras, el romanticismo, comparte espacio con la aparición de los primeros ejemplos de las corrientes que nos habrán de conducir hasta su final, esto es el realismo y el simbolismo. A caballo entre el primero y el segundo se encuentra el Viaje a Oriente de Gustave Flaubert, realizado entre 1849-1851, quien llega a Damasco a finales del verano de 1850. El romanticismo se deriva de la actitud vital de escritor francés, que toma la iniciativa de repensar el mundo a través del arte, para lo que debe abstraerse de la realidad europea y desde la distancia poder criticarla. Esta postura había estado presente desde el punto de vista estético en la primera redacción de L'éducation sentimentale y en La Tentation de Saint Antoine, obra que terminó justo antes de emprender su viaje. En realidad, su libro de viajes eran más bien cuadernos de notas, que no fueron editados como libro hasta después de su muerte. Ello justifica que en muchas ocasiones sólo sean apuntes rápidos que dejan constancia de algunas vicisitudes del viaje o de su estancia en la ciudad, pero es en la combinación de ese esquema con la utilización de un lenguaje descriptivo y preciso donde observamos de manera incipiente la escritura que caracteriza su gran novela, Madame Bovary, la cual comenzó a escribir tras este viaje.

De là ont a toute la vue de Damas, ville blanche, avec ses minarets pointus, au milieu de l'immense verdure qui l'entoure ; à la ville se rattache dans le vert une longue raie blanche: c'est l'interminable faubourg que nous avons suivi quand nous sommes arrivés de Jaffa, et toute cette verdure est entourée du désert, entourée de montagnes. Nous essayons de revenir par un chemin, nous nous perdons et arrivons à la porte d'un jardin; nous avons reboussé chemin, pris la route pavée de Beyrouth, et après avoir traversé toute la ville, les chiens commençait a grogner, nous sommes rentrès chez nous, le soleil étant couché. (Flaubert 1974: 593-594)

La creciente presencia occidental en la zona se traducirá también, como constata el propio Flaubert, en una disminución del fundamentalismo religioso, y entre otras cosas dejó de estar prohibido para los no musulmanes entrar a la ciudad subidos sobre la montura. Este hecho es destacado por Domingo Arosemena que emprende su viaje en 1855. Originario de la que, contemporáneamente, era la República de Nueva Granada, los actuales Colombia y Paraguay, tituló a su obra Sensaciones en Oriente ó Ympresiones bíblicas de un granadino en Tierra Santa, que fue publicada en Nueva York en 1859. El testimonio de Arosemena 
supone una perspectiva diferente de la que cundía en su tiempo, con una recuperación del viaje a Oriente con valor de peregrinación, donde lo que interesa es pisar la tierra de Jesucristo y de los primeros profetas, en una búsqueda de los orígenes religiosos. Además, el autor está también determinado por el talante nacionalista del discurso oficial en las recientemente independizadas colonias hispanoamericanas. Sus palabras del prefacio son reveladoras en ambos sentidos:

Desde luego sería feliz si con mi obra pudiera inculcar estas verdades, en el corazon de algunos niños que desde la infancia dudan de las cosas sagradas, i suponen fabulosos los hechos de la Biblia referidos. Es por esta razon que ofresco al Clero de mi Patría este pequeño volumen que contiene las nociones que hé recibido en su escuela desde mí infancia, ensanchadas despues en las fuentes del Cristianismo, como un testimonio sincero de mi gratitud, para que como órganos de la civilizacion nacional, puedan propagar con mas facilidad estas verdades immutables, que son destinadas para todos los siglos, quien tiene el gusto de suscribirse mientras tanto siempre afectisimo compatriota. (Arosemena 1859: V)

Para Arosemena el suceso más importante de la historia de Damasco es por supuesto la conversión de San Pablo (Arosemena 1859: 63), y como le ocurrió al malogrado George Robinson, la vista de la ciudad mejora proporcionalmente a la distancia en la que se sitúa observador: "Dos horas escasas son necesarias para descender á las puertas de la poblacion, cuyo aspecto, imponente desde léjos, hace perder toda la ilusion del panorama que se presenta ántes de conocerla" (Arosemena 1859: 56).

A pesar de que desde este momento y en adelante los viajeros ya no tendrán que entrar a pie en la ciudad, el proceso de occidentalización que viene sufriendo el Imperio en esta segunda mitad de siglo no se producirá de la misma manera en todos lados. Lo todavía penoso de las comunicaciones terrestres en esa época hizo que mientras unas ciudades portuarias sufrían ese proceso de modernización, otras del interior, como Damasco, permanecieran aisladas; además de la "resistencia al cambio" con la que históricamente es caracterizada. Ello le hizo permanecer como la joya de Oriente, la ciudad oriental por antonomasia para los viajeros (Martín Asuero 2004: 24). La primera de estas dificultades será atenuada en 1863, con la construcción de la carretera que la unirá con Beirut, uno de los principales puertos hacia Europa, además de ir mermando paulatinamente también la segunda. Con ella el viaje desde allí será mucho más cómodo y rápido. Una diligencia salía todas las mañanas a las cuatro y llegaba a Damasco a las cinco y media de la tarde, con once paradas intermedias (Martín Asuero 2004: 62), como así constatan los viajeros de la época. 
Los epígonos del romanticismo que transcurren contemporáneamente a la nueva mirada realista se producen en muchos casos de la mano del romanticismo hispánico, algo más tardío que el europeo. El diplomático y escritor vasco Adolfo Mentaberry vivió en la ciudad siria donde ocupó el cargo de vicecónsul en 1867, poco tiempo después de la apertura del primer consulado español. Fruto de sus dos actividades es el estilo de su relato de viajes, Viaje a Oriente, de Madrid a Constantinopla, donde confluyen un importante influjo romántico y un marcado carácter colonialista.

A partir de la década de los sesenta comenzarán a abrirse los consulados europeos en Damasco, lo que traerá de nuevo un relato de viajes de carácter oficial, como en el caso de Mentaberry, escrito por diplomáticos. Entre ellos destaca también el que fue cónsul inglés de Damasco desde 1868 hasta 1871, Richard Francis Burton, además traductor -fue el primero en traducir las Mil y una noches al inglés-, explorador y orientalista. Hablaba casi treinta lenguas (el número varía en una o dos según la fuente a la que se acuda). Su leyenda es tan grande como la de Ali-Bey. Viajó a la Meca en la caravana de Damasco haciéndose pasar por musulmán en la década de los 50 . Su nombramiento como cónsul despertó muchos recelos en la ciudad a causa de su herejía, pero una vez que ocupó el cargo fue un personaje muy querido según cuentan las crónicas.

Durante las últimas décadas del siglo XIX se van a producir dos cambios importantes en las circunstancias materiales que determinarán, no sólo el carácter del viaje, sino el devenir de las rutas comerciales y la basculación de los centros de interés para los gobiernos occidentales. El primero de ellos se produjo en la época del consulado de Burton: nos referimos a la apertura del canal de Suez en 1869. El segundo, en 1895, es la apertura de la línea férrea entre Beirut y Damasco. Es también el periodo donde se inicia el uso del barco a vapor, y la aparición de las primeras cámaras fotográficas portátiles, lo que deriva en un importante desarrollo de todo lo relacionado con la industria turística: hoteles, restaurantes, agencias de viajes, guías... (Martín Asuero 2004: 44). Con estas condiciones, el viajero Pierre Loti encuentra a su llegada "le mouvement, la gaieté d'une ville quelconque accessible à tous, d'une ville qui sera bientôt aussi européanisée que Constantinople" (Loti 2008: 142), o más adelante:

Ce n'est pas qu'il ne reste encore des étrangetés charmantes, dans ce labyrinthe de petites rues occupant, au milieu de l'oasis, l'espace d'une capitale. Le quartier des hôtels, où nous avons mis pied à terre en arrivant et qui a tant déçu nos yeux, n'est qu'une sorte d'entrée négligeable, á l'aboutissement de la voie qui relie la ville au grand port européanisé de Beyrouth. (Loti 2008: 143) 
Loti es perfectamente consciente de cómo los avances en los medios de comunicación que se han producido recientemente van a cambiar la realidad del viaje y la de los destinos, lugares exóticos que inevitablemente dejarán de serlo. Además él, como sujeto, busca en el viaje la adaptación a las circunstancias de la cultura que visita como incentivo para una mejor y más verdadera experiencia de la alteridad, que se conjuga con una postura hedonista ante las experiencias que en sus destinos ha de vivir: "no hay dios, no hay moral, nada de lo que se nos ha enseñado a respetar existe; hay una vida que pasa, a la cual es lógico que le pidamos lo más de goce que sea posible" (Todorov 1991: 352) La conclusión que se extrae de sus reflexiones, según Todorov, es que para que exista el exotismo, es necesario que los pueblos permanezcan alejados unos de otros (Todorov 1991: 357).

Los avances en los medios de transporte hacían que ya no fuese necesario contratar un gran séquito con camellos, servicio y mercancías, como Lamartine, ni viajar durante varios años, sino que los viajes se podían hacer de una duración mucho más corta, utilizando el vapor y después el tren para llegar a la ciudad. Es así como surge otro tipo de relato de viajes, la crónica periodística, que el viajero podía hacer llegar a sus lectores mediante el correo en pocos días.

De esta forma, en tren, llega a Damasco Enrique Gómez Carrillo, para quien la ciudad dista mucho de irradiar el encanto del que dan cuenta los relatos románticos. La cita, aunque algo extensa, nos presenta un cuadro único de la ciudad a caballo entre ambos siglos, que se debate entre el fin de un modelo urbanístico que ha permanecido durante siglos y el despunte de una urbe modernizada y que apunta a la futura globalización:

Cuando penetramos en la ciudad y comenzamos a pasearnos, la delicada ilusión se desvanece. ¿Dónde están los jardines?... ¿Dónde las terrazas floridas? [...]. Ahí va el río de todas las canciones y de todas las esperanzas, el río casi sagrado que hace soñar durante las noches solitarias a los caballeros del desierto, el dulce Baradá, de aguas turquesas... Mas, para no mentirnos a nosotros mismos, tenemos que confesar que no es sino un arroyo turbio y lento, que pasa bajo vulgares puentes de hierro. [...] iOh desencanto de los desencantos! Hoy no vemos ahí sino grandes casas de estilo europeo, hoteles alemanes y suizos, edificios municipales, almacenes enormes cuyos rótulos son copias de los de París; y para completar el cuadro, un tranvía eléctrico, un endiablado tranvía que pasa sonando sus campanillas [...]. ¿Estamos realmente en Oriente? Esta formidable columna de hierro que se alza ahí cubierta de trofeos, celebra no una victoria de los príncipes ommiadas, sino una victoria del progreso. [...] Verdaderamente, me digo, más me hubiera valido imitar a Mahoma y no entrar en este paraíso, de lejos tan bello, de cerca tan vulgar. (Martín Asuero 2004: 86) 
Si por un lado el orientalismo y lo exótico están en uno de sus momentos de más producción e influencia, a caballo entre ambos siglos, con los viajes de Pierre Loti, Gauguin, o la inclusión de motivos y estéticas de este género por parte de las vanguardias posteriormente -Picasso, Matisse, Kandinsky-, por otro se están sentando las bases para una futura crisis del concepto de exotismo ante la perspectiva de un mundo que se va empequeñeciendo a medida que se coloniza su espacio físico, transformándolo en familiar, y a medida que la sociedad capitalista se va expandiendo. En Oriente, esto se traduce en la creciente presencia francesa e inglesa durante el siglo XIX, que se certifica con su ocupación tras la I Guerra Mundial. Durante las primeras décadas del XX la ciudad se puebla de edificios modernos como las estaciones, carreteras, bulevares, abandonado definitivamente su imagen compacta propia de las urbes del islam.

Precisamente durante esta contienda, Damasco será el cuartel general de las fuerzas de la alianza turco-germana contra Gran Bretaña, lo cual la convertirá en un objetivo ineludible. A los destrozos que sufre la ciudad en este periodo hay que sumarle los que ocasionaron el bombardeo de las tropas francesas en 1926. Con sus nuevos ocupantes, será remodelada con un proyecto del urbanista Danges, en el que participó también Michel Ecochard, al cual se le deben varios decenios de intervenciones urbanísticas en la capital. Éstas estuvieron basadas principalmente en la voluntad de preservar el mayor número posible de monumentos, y tratando al mismo tiempo de unir la ciudad antigua con las zonas modernas.

La ocupación francesa daría el impulso definitivo a su apertura hacia occidente y los viajeros y escritores de la época no dejarán de visitarla. En 1928 lo hizo la novelista Agatha Christie, quien llegó, con cuarenta años de edad en el Orient Express, para iniciar en Oriente la que será su pasión en adelante, la arqueología, además de descubrir un escenario único que marcará su escritura en adelante (Morató 2006: 357). En el mismo año la visitó la también escritora y exploradora británica Freya Stark, pero mientras la primera se alojaba en el hotel Orient Palace, esta lo hacía en una modesta casa del barrio de Bab Tuma (Morató 2006: 309). Las posibilidades que en este momento se brindaban al ya turista eran muchas, se habían multiplicado enormemente y los servicios que demandaban los occidentales proliferaron por toda la ciudad, de manera que cada uno podía vivir la experiencia del viaje más que como un acercamiento a la alteridad, como un reflejo de su propia vida.

Con esta realidad ya perfectamente implantada, el viajero era consciente de que no tenía relación alguna con el lugar que visitaba, y más aún, una postura ética ante sus lectores le obliga a hablar de esa condición en sus relatos (Almarcegui 2004: 108). En lo que a la ciudad concierne, se toma una definitiva conciencia de que, el espacio 
real, visitado, es radicalmente distinto de un espacio puramente literario que es el que construye el texto, o como lo ve Pierre Brunel, que "le récit de voyage s'organise en une autobiographie où la ville réelle se mêle à la vie imaginée" (Brunel 1986: 10). Es así como siente esa experiencia Colin Thubron, cuya Semblanza de Damasco es uno de los testimonios más completos del siglo XX sobre la ciudad, gracias a su exhaustivo estudio y conocimiento documental, que no deja hechos sin registrar desde las primeras hipótesis de su fundación y hasta el momento de su viaje, pero también a sus agudas observaciones y al lirismo y la belleza de sus pasajes descriptivos. Esta perspectiva es la que le permite no dejarse engañar por las expectativas, consciente de esa muerte del exotismo, y al mismo tiempo apreciar lo que de original y único permanece en ella: "Damasco conserva un carácter original y extraordinario mucho más genuino que cualquier otra ciudad del Oriente Medio, aunque, inevitablemente, la antigua personalidad vaya difuminándose en el anonimato de la modernidad" (Thubron 2002: 18). Es en los pasajes líricos donde las imágenes de la ciudad recobran toda su belleza, en un estilo pretendidamente colorido, que le acercan al tono de las descripciones de Lawrence Durell a propósito de Alejandría, a la estética del realismo mágico: "Damasco, salpicada de luces, se ahogaba en vientos fríos. La luna descubrió una aspereza dentada en el monte y abrió sus venas blancas en la sombra" (Thubron 2002: 248).

Desde la segunda mitad del siglo XX, tras la Segunda Guerra Mundial, la proyección a escala mundial de la democracia occidental, la apertura de los mercados internacionales, etc., sumado al gran avance en materia de transportes que este siglo supone, vuelve a poner en circulación el flujo de personas y la importancia de las escrituras del viajero, con las características propias que le otorgará la cultura de masas. Desde la segunda mitad del siglo XX conocemos el globo más que a través de los libros de viajes, a través de la televisión o la prensa. Es por todo ello que este tipo de literatura presentará unas características que le son propias y la alejan de su formato y funciones anteriores.

Por un lado, el autor de libros de viajes se enfrenta a la circunstancia de que la realidad geográfica de nuestro planeta es, en mayor o menor medida y según el lugar al que nos refiramos, conocida por sus lectores, cumpliéndose lo que ya pronosticara Loti un siglo atrás. Además, en algunos casos, si no se trata de un diario de viaje, cuya característica sería la inmediatez, cuando el libro se concluye mucho después de haber finalizado el viaje, como lo es el caso de Regás, entra en juego el recuerdo y la transformación en escritura del mismo, que por supuesto no es exactamente, o tal vez no lo es para nada, equivalente a las sensaciones y pensamientos que el autor pudo tener delante de determinado monumento o lugar. 
El lector, otrora ajeno de los lugares que se narraban, al final del siglo XX será un sujeto informado, al menos en superficie, por lo que, en lo que sería en un primer nivel un discurso puramente informativo, el autor da cuenta en profundidad de la historia y características del lugar de una forma completa y documentada, como hace Thubron y como sucede también con el último de los viajeros que exponemos, Rosa Regás, quien publica en 1995 su libro Viaje a la luz del Cham. Damasco, El Cham, un pedazo de tierra en el paraíso. Los mecanismos de oposición y comparación entre los dos legados culturales, el de la autora y el de la ciudad que visita, serán una de las constantes del relato. Otro será un imposible, la huída de un modelo determinado de viaje, el del turista, en busca de otro, que si bien ya poco tiene que ver con la búsqueda del idealismo decimonónico que plantea el exotismo, aparecerá desde el comienzo del viaje como un medio para aproximarse de la manera más certera posible a la realidad que le rodeará en los dos meses siguientes a su llegada.

De esta manera, el estilo no será uniforme y variará en función de las posibilidades del objeto, debatiéndose entre: la utilización de un estilo casi periodístico, inherente a los medios de comunicación de finales del siglo XX y caracterizado por un tratamiento ágil de la información, que se pretende objetivo pero que no deja de ser sesgado; y un estilo de carácter más poético si se quiere, y cuya propia condición de literalidad excusa de alguna forma que surjan deliberadamente los leitmotiv del imaginario exótico de la urbe:

Damasco la reina del agua, dicen las guías, la de las tierras fértiles, la de los cielos benignos. Como una esmeralda verde en medio de un desierto de arenas doradas se abre al este de la cordillera del Antilíbano que de norte a sur corre paralela al mar. La esmeralda es su oasis que a pesar de haber sido invadido sin miramientos por la ciudad y el desarrollo indiscriminado, todavía conserva, antes de convertirse abruptamente en desierto, huertas y riberas frondosas, campos de violetas, rosas damascenas y mimosas, sembrados y labrantíos, extensiones de frutales, higueras y olivos, y caminos bordeados de nogales, un paraíso ya descrito por Alí Bei al Abbasi hace casi doscientos años. Pero la ciudad, Damasco, no es verde, sino dorada, del color de la tierra, del ocre tostado de los colores antiguos. Una ciudad profundamente árabe, un abigarrado y primitivo núcleo de callejuelas, casas y patios escondidos en ellas que desde hace cuatro mil años sin interrupción ha ido creando a su alrededor círculos de vida arañándole tierra al oasis. (Regás2003: 63) 


\section{Bibliografía}

ALI-BEY (1982): Viajes por Arabia, Palestina, Siria y Turquía. Barcelona: Olañeta.

ALMARCEGUI, Patricia (2004): "La metamorfosis del viajero a Oriente". Revista de Occidente, núm. 240, pp. 105-117.

ALMARCEGUI, Patricia (2007): Alí Bey y los viajeros europeos a Oriente. Barcelona: Bellaterra.

AMRAM, Rica (2007): "El Libro de viajes de Benjamín de Tudela: del mito a la realidad histórico-geográfica". CEHM, núm. 30, pp. 13-24.

AROSEMENA, Domingo (1859): Sensaciones en Oriente o Ympresiones bíblicas de un granadino en Tierra Santa. Nueva York: Robert Craighead.

AUGÉ, Marc (1996): El sentido de los otros. Barcelona: Paidós.

AUGÉ, Marc (1998): El viaje imposible. El turismo y sus imágenes. Barcelona: Gedisa.

BALARD, Michel (1988): "L'Orient: concept et images dans l'occident médiéval", en L'Orient: concept et images. XVe Colloque de I'Institut de Recherches sur les Civilisations de I'Occident Moderne. Paris: Université de Paris IV-Sorbonne.

BENEVOLO, Leonardo (1995): Histoire de la ville. Marseille: Parenthèses.

BRUNEL, Pierre (1886): "Préface", en François Moureau (ed.), Métamorphoses du récit de voyage: Actes du Colloque de la Sorbonne et du Sénat (2 mars 1985). Genève: Slatkine.

BURCKHARDT, Johann Ludwig (1822): Travels in Syria and the Holy Land. London: John Murray.

FLAUBERT, Gustave (1974): Par les champs et par les grèves; Voyages et carnets de voyages. Fuvres complètes, tome 10. Paris: Club de I'Honnête Homme.

FRESCOBALDI, Lionardo di Niccolò (1818): Viaggio di Lionardo di Niccolò Frescobaldi in Egito e in Terra Santa. Roma: Carlo Mordacchini.

GONZÁLEZ ALCANTUD, José Antonio (1988): "Teoría del exotismo" [en línea]. Gazeta de Antropología, núm. 6, artículo 2. En: http://digibug.ugr.es/handle/10481/13745 [Consulta: abril de 2011].

GONZÁLEZ ALCANTUD, José Antonio (1989): El exotismo en las vanguardias artísticas. Barcelona: Anthropos.

GRAÇA, Luis (1983): A visao do oriente na literatura portuguesa de viagens: os viajantes portugueses e os itinerários terrestres (15601670). Lisboa: Imp. Nac. Casa da Moneda.

GUERRERO, Francisco (1593): El viaje de Hiervsalem que hizo Francisco Guerrero. Valencia: Hered. de Ioa Navarro.

LAMARTINE, Alphonse (1843): Voyage en Orient 1832-1833. Deuxieme partie. Paris: Charles Gosselin.

LITVAK, Lily (1986): El sendero del tigre: Exotismo en la literatura española de finales del siglo XIX (1880-1913). Madrid: Taurus.

LITVAK, Lily (2004): "Topografía de la otredad. Estrategias de la escritura en las crónicas de viaje del siglo XIX". Revista de Occidente, núm. 240, pp. 92-104.

LOTI, Pierre (2008): La Galilée. Paris: Payot.

MANDEVILLE, John (1839): The voiage and travile of John Maundevile. London: Edward Lumley. 
MARTÍN ASUERO, Pablo (2004): Descripción del Damasco Otomano (18071920) según las crónicas de viajeros españoles e hispanoamericanos. Madrid: Miraguano.

MORALES OSORIO, Susana; y FERNÁNDEZ HOYOS, Sonia (2006): "El mediterráneo a través de la ficción: el extraño caso de Sir John Mandeville". Anuario de Estudios Medievales, 36/1, enero-junio de 2006, pp. 335-354.

MORATÓ, Cristina (2006): Las damas de oriente: grandes viajeras por los países árabes. Barcelona: Debolsillo.

POCKOCKE, Richard (1772): Voyage en Oriente. Paris: J. P. Costard.

REGÁS, Rosa (2003): Viaje a la luz del Cham: Damasco, El Cham, un pedazo de tierra en el paraíso. Madrid: Siete Leguas.

RIVADENEYRA, Adolfo (2006): Viaje de Ceilán a Damasco. Madrid: Miraguano.

ROBINSON, George (1837): Travels in Palestine and Syria, vol. 2. London: Henry Colburn.

SCHILBERGER, Johann (1966): Bondage and travels of Johann Schilberger. New York: Burt Franklin.

SEGALEN, Victor (1999): Essai sur l'exotisme. Paris: LGF.

SORIANO NIETO, Nieves (2009): Viajeros románticos en Oriente: Delacroix, Flaubert, Nerval. Murcia: Universidad de Murcia.

SOURIAU, Etienne (1998): Diccionario Akal de estética. Madrid: Akal.

STANHOPE, Lady Hester (1846): Travels of Lady Hester Stanhope. London: Henry Colburn.

THÉVENOT, Monsieur de (1674): Suite de voyage en levant. Seconde partie. París: Charles Angot.

THUBRON, Colin (2002): Entre árabes: Semblanza de Damasco; Las montañas de Adonis. Barcelona: Península.

TODOROV, Tzvetan (1991): Nosotros y los otros: ensayo sobre la diversidad humana. México: Siglo XXI.

TOLLINCHI, Esteban (1989): Romanticismo y modernidad. Ideas fundamentales de la cultura del siglo XIX. San Juan: Universidad de Puerto Rico.

TORRE, Guillermo de (2001): Literaturas europeas de vanguardia. Sevilla: Renacimiento.

TUDELA, Benjamín de (1982): Libro de viajes de Benjamín Tudela. Barcelona: Riopiedras.

VARTHEMA, Ludovico di (2004): Le voyage de Lodovico di Varthema en Arabie \& aux Indes orientales (1503-1508). París: Chandeigne.

YOUSSEF, Aida (1993): Cultura, espacio y organización urbana en la ciudad islámica. Madrid: Instituto Juan de Herrera. 